\title{
Oratorio de los reyes y sus conquistas: retratos y folletos recortados por Diogo Barbosa Machado
}

\author{
Rodrigo Bentes Monteiro \\ Universidade Federal Fluminense, Río de Janeiro \\ rodbentes@historia.uff.br
}

Fecha de recepción: 11/11/2013

Fecha de aceptación: 06/04/2014

\begin{abstract}
Resumen
El artículo examina las llamadas colecciones de retratos y folletos organizadas por el bibliófilo portugués Diogo Barbosa Machado (1682-1772), hoy depositadas en la Biblioteca Nacional de Brasil, en Río de Janeiro, a la luz de su experiencia como clérigo oratoriano y como miembro de la Academia Real da História Portuguesa, a mediados del siglo XVIII. Lejos de una simple contextualización social, se pretende llevar a cabo un análisis atento a las percepciones sobre la forma y el contenido de los conjuntos documentales considerados, tanto dentro como fuera de los ámbitos principales en los que se integraba su coleccionador. Se espera así poder comprender mejor sus peculiaridades y elementos comunes, así como las expectativas puestas en la historia que elaboró sobre la monarquía portuguesa y sus conquistas.
\end{abstract}

Palabras clave: Diogo Barbosa Machado, Congregación del Oratorio, Academia Real da História Portuguesa, Monarquía portuguesa.

\section{Oratory of the kings and their conquests: pictures and leaflets collected by Diogo Barbosa Machado}

\begin{abstract}
This paper analyzes the so-called collections of pictures and leaflets organized by the Portuguese bibliophile Diogo Barbosa Machado (1682-1772), today preserved at the National Library of Brazil in Rio de Janeiro. The analysis considers Barbosa Machado's experiences both as an Oratorian cleric and as a member of the Royal Academy of Portuguese History in the mid-eighteenth century. Going beyond a mere social contextualization, the study considers the cultural and social history of the collections and the perceptions to which they were subjected, in form and in content, within and outside the main milieus that Barbosa Machado belonged to. This allows us to gain a better understanding of their peculiarities and common features, as well as the expectations the collector placed on his history of the Portuguese Monarchy.
\end{abstract}

Key words: Diogo Barbosa Machado, Congregation of the Oratory, Royal Academy of Portuguese History, Portuguese Monarchy 
¿En qué medida una colección particular refleja los ideales de grupos mayores? En otras palabras, ¿qué lugar ocupa el individuo coleccionista en una sociedad de matriz estamental? En una selección de imágenes y escritos, ¿dónde estarían las fronteras entre lo religioso y lo político? ¿Cabría identificar en ella un vector predominante a la hora de elaborar una historia de Portugal? El presente artículo pretende abordar estas cuestiones mediante el estudio de los retratos y folletos recopilados por el académico real y clérigo Diogo Barbosa Machado (1682-1772), más conocido por su Bibliotheca Lusitana, una obra bastante consultada por aquellos investigadores que, interesados en el Antiguo Régimen portugués, buscan informaciones sobre sus autores y sus obras ${ }^{1}$.

En realidad, el oratoriano y miembro de la Academia Real da História fue también un dedicado bibliófilo, habiendo reunido aproximadamente 4300 obras en 5700 volúmenes. Al final de su vida, el abad de Santo Adrião de Sever donó su librería a la Real Biblioteca de los Braganza, entonces en proceso de recomposición, como consecuencia de los daños producidos por el terremoto de 1755 que asoló Lisboa. En 1810, la biblioteca de los reyes de Portugal -y, con ella, la de Barbosa Machadosalió en cajas hacia Río de Janeiro, después de que la corte portuguesa se trasladase a los trópicos. En los acuerdos que ratificaron la independencia del Brasil, en 1822, el emperador Pedro I (1822-1831) compró casi la totalidad de este acervo, transformándolo en Biblioteca Imperial y, desde 1870, durante el reinado de D. Pedro II (18311889), en Biblioteca Nacional.

\section{COLECCIÓN SINGULAR Y ESTIMADA}

Cabe destacar dos partes o conjuntos de la antigua librería de Diogo Barbosa Machado, hoy depositados en las secciones de iconografía y obras raras de la Biblioteca Nacional de Brasil. Consiste, por un lado, en seis álbumes de retratos de reyes, reinas, príncipes y varones insignes de Portugal (en "virtudes y santidad", en "letras, artes y ciencias" y "en campaña y gabinete"), que contienen 1382 grabados recortados, ordenados de modo cronológico y temático, y ornamentados muchos de ellos con orlas variadas y con escritos impresos, también recortados y retirados de otras obras, colocados a modo de epigramas en latín o en portugués. Los seis tomos presentan portadas impresas con letras en negro y rojo. Los dos primeros datan de 1746 y los demás carecen de fecha. Por otro lado, se trata de $c a$. 3185 opúsculos impresos entre 1505 y 1770, sobre temas diversos relacionados con la monarquía, la sociedad de corte y el imperio ultramarino portugués, agrupados en 146 tomos no numerados (dos de ellos se extraviaron) y clasificados en: genetlíacos, relatos de sucesos, elogios oratorios y poéticos, sermones de nacimientos, aniversarios y matrimonios, funerales y autos de fe, entradas, oraciones por la salud, biografías y genealogías, así como autos de reuniones de cortes y aclamaciones, noticias de batallas y cercos militares, manifiestos y tratados políticos, misiones religiosas y villancicos. Los opúsculos siguen

1 Barbosa Machado, D.: Bibliotheca Lusitana, historica, critica e chronologica, Lisboa, Antonio Isidoro da Fonseca (t. I)-Ignacio Rodrigues (t. II y III)-Francisco Luiz Ameno (t. IV), 1747-1759. 
además una disposición cronológica y espacial, por continentes. La mayoría de los tomos presenta portadas impresas y sumarios manuscritos, con letra del siglo XVIII, que contienen la lista de los opúsculos encuadernados ${ }^{2}$.

No hay noticia de colecciones semejantes que se hayan preservado de igual modo en Portugal o en España ${ }^{3}$. En relación con los retratos, los grabados normalmente se conservan sueltos, incluso cuando en el pasado figuraron en volúmenes encuadernados que hoy se han perdido. En la Biblioteca Nacional de Portugal hay nueve álbumes con más de 1500 grabados, organizados por un eclesiástico anónimo en 1791 y probablemente incorporados a este acervo durante la revolución liberal. En dichos álbumes, los grabados con retratos de reyes, gobernadores de la India, clérigos y varones ilustres portugueses están en su mayoría recortados y enmarcados por una orla impresa con tampón ${ }^{4}$. No obstante, su elaboración y ornamentación son menores con respecto, por ejemplo, a los dos tomos de retratos de reyes y príncipes reunidos por Diogo Barbosa Machado. En la Biblioteca del Palacio Real, en Madrid, hay varios álbumes de retratos con grabados producidos durante el Antiguo Régimen. Con todo, fueron encuadernados en el siglo XIX, sin el orden y la ornamentación de la colección que aquí analizamos ${ }^{5}$. En la Biblioteca Nacional de España, se pueden consultar

2 En el catálogo manuscrito de su librería, bajo "História Profana”, los opúsculos aparecen comentados como una colección singular y muy estimada de sucesos de la historia de Portugal, formada por varios libros en prosa y verso. Bajo el epígrafe "Discursos Concionatórios" se encuentran los tomos con los sermones, siendo muchos de ellos raros y antiguos. Y en "Poetas Portugueses, Castellanos e Italianos" se incluyen los tomos con villancicos. Los tres tomos relativos a relatos de embajadas no constan en el catálogo, probablemente por olvido del autor. Aunque separados u omitidos en esta lista, la organización de los tomos con los sermones, villancicos y relatos de embajadas siguió los mismos criterios y el mismo tratamiento que el grupo principal. Al final, los álbumes de los reyes, reinas y príncipes de Portugal (2 tomos) y los de los retratos de varones portugueses insignes en santidad, literatura, ciencia militar y policía (4 tomos), son descritos como siendo de mucha estima por la rareza de muchos de los retratos y porque, en su mayor parte, estaba entre "orlas primorosas", aumentando mucho las figuras representadas. Aún existen en la librería dos tomos de retratos diversos, de personajes de la historia mundial, sobre todo, europea, posteriormente asociados al conjunto principal de otros seis tomos. No hacen referencia, sin embargo, a la historia de Portugal, recibieron un trato distinto por parte del coleccionista y fueron descritos de forma separada en el catálogo. BARBOSA MACHADO, D.: Cathalogo dos livros da livraria de Diogo Barbosa Machado distribuídos por elle em materiais e escrito por sua própria mão, Biblioteca Nacional do Brasil (BNB), Ms. 15, 1, 002, fols. 33-34, 64-64r, 73 y 112r. Disponible en: http://objdigital.bn.br/acervo_digital/div_manuscritos/mss1277751/mss1277751.pdf (acceso: 20/10/2013).

3 Se han consultado los siguientes fondos: Biblioteca da Ajuda, Lisboa; Biblioteca Nacional da Portugal; Biblioteca Pública de Évora; Biblioteca Geral da Universidade de Coimbra; Biblioteca Pública Municipal do Porto; Real Biblioteca del Palacio Real de Madrid y Biblioteca Nacional de España, en la que el análisis detallado de los folletos aún está por hacer. En la actualidad, coordino junto a Tiago Miranda un proyecto que pretende estudiar en detalle la Biblioteca do Palácio Nacional de Mafra.

4 Los álbumes, no numerados, llevan en las portadas textos manuscritos en tinta china; las orlas impresas que rodean los retratos son xilografías que se ajustan el tamaño de los grabados recortados; el papel es del siglo XVIII; el orden de los retratos es cronológico, aunque se reinicia em cada uno de los volúmenes. Series potentissimori regum Lusitania e iconibus illustrata...; Series regum, et principum Lusitanorum iconibus illustrata...; Retratos dos vice reys, e governadores da Índia...; Retratos de cardeais, bispos, e varoens portugueses ilustres em nobreza, armas e santidade...; Effigies S. R. E. cardinalium..., 3 tomos; Chronologia summorum Romanorum pontificum...; Ministri generales, pontifices \& cardinales.... Biblioteca Nacional de Portugal (BNP), E. A. 1A-E. A. 9A.

5 Sobre la Real Biblioteca del Palacio Real de Madrid, véase LóPEz-Vidriero, M. L.: "La Biblioteca del Palacio Real de Madrid", Archives et bibliothèques de Belgique, LXIII, 1-4 (1992), pp. 85-118; ID.: "La librería de cámara en el palacio nuevo", López-Vidriero, M. L. y CÁtedrA, P. M. (orgs.): El libro antiguo 
los dibujos, estampas y manuscritos coleccionados por Ceán Bermúdez (1749-1829), que, sin embargo, hoy se encuentran dispersos, siendo apenas inteligibles como colección a través de catálogos 6

La colección de retratos de Barbosa Machado no parece realizada por un connoisseur, sino por un compilador, pues en ella los criterios de cantidad a la hora de reunir grabados prevalecieron sobre los de calidad. Hay muchos retratos repetidos y varios son de factura menor ${ }^{7}$. Aunque no tenga el perfil de una galería de retratos de hombres ilustres, al modo de los dibujos de Francisco Pacheco (1564-1644) ${ }^{8}$, la conjugación artesanal que hace entre imagen y texto (los epigramas), a la que se suma en muchos casos un tercer elemento (las orlas), le confiere originalidad. Además, todo el material proviene de otras fuentes impresas, habiendo sido recortado y pegado según el arbitrio del coleccionador, y siendo escasas las intervenciones posteriores que ha sufrido. Pocos son los retratos que se extraviaron cuando los álbumes aún estaban en la Real Biblioteca de Ajuda y pocos los que se le añadieron en Portugal o en Brasil. La restauración que se llevó a cabo a finales del siglo XIX, si por un lado realizó nuevas encuadernaciones y corrigió a mano los huecos vacíos de las portadas impresas originales (algo impensable en la actualidad), por otro, conservó la concepción original que el clérigo y académico real tuvo de esta colección y que expresaba su visión del mundo, como consta en el catálogo que entonces se publicó en los Anais da Biblioteca Nacional ${ }^{9}$.

En lo que a los folletos impresos se refiere, denominados sucesos por el coleccionador, las varias misceláneas existentes en las bibliotecas públicas de Portugal surgieron cuando los monasterios y conventos fueron expoliados, en 1834, durante la reforma liberal. Estas grandes recopilaciones de opúsculos encuadernados se vieron incrementadas por medio de donaciones posteriores o mediante compras, conformando así nuevos volúmenes y alterando sus perfiles originales. En la Biblioteca del Palácio Nacional de Mafra, relativamente preservada desde su organización en el siglo XVIII y ajena a los daños del terremoto, la Biblioteca Volante organizada por el franciscano Mathias da Conceição, entre 1736 y 1760, reunió en -supuestamente- 164 volúmenes una cantidad considerable de folletos y varios manuscritos, cuya exacta dimensión aún está por definir. No obstante, a esta colección también se le añadieron posteriormente nuevos opúsculos, además de tener un perfil bastante ecléc-

español. El libro en palacio y otros estudios bibliográficos, Salamanca, Ediciones Universidad de Salamanca/ Patrimonio Nacional/Sociedad Española de Historia del Libro, 1996, pp. 167-187; ID.: “Apuntes sobre la Librería de Cámara”, Arbor, CLXIX, 665 (2001), pp. 287-295; e ID.: Specvlvm principvm. Nuevas lecturas curriculares, nuevos usos de la Librería del príncipe en el Setecientos, Madrid, Biblioteca Nueva, 2002.

6 PÁez, E. S.: El gabinete de Ceán Bermudez. Dibujos, estampas y manuscritos de la Biblioteca Nacional, Gijón, Museo-Casa Natal de Jovellanos, 1997. Coleccionar retratos grabados de personajes y recortados de otras obras parece haber sido habitual en la Inglaterra del siglo XVIII. No obstante, a partir de las fotografías de los grabados que se reproducen en el libro consultado, se constata que no se hizo uso de orlas recortadas como en la colección Barbosa Machado; Pointon, M.: Hanging the head. Portraiture and social formation in Eighteenth-century England, New Haven/Londres, Yale University Press, 1993, pp. 53-78.

7 FARIA, M. F.: "Colecção de retratos de Diogo Barbosa Machado", Artis (2009), pp. 361-384.

8 Casal, M. P. C.: Francisco Pacheco y su Libro de retratos, Madrid, Marcial Pons, 2011.

9 Brum, J. Z. M.: "Catálogo dos retratos coligidos por Diogo Barbosa Machado", Anais da Biblioteca Nacional, 16-18, 20-21 y 26 (1889-1893, 1896, 1898-1899 y 1904). 
tico cuando se la compara con la colección de Barbosa Machado ${ }^{10}$. Ésta nítidamente se elaboró -tanto en los retratos como en los folletos- en torno a asuntos que tocaban a la monarquía, a los grupos de elite y a las conquistas ultramarinas de Portugal, desde la fundación del reino en el siglo XII hasta el periodo de José I (1750-1777), siendo escasas las incorporaciones y añadidos de documentos relativos a los reinados posteriores (apenas en los retratos).

En la Biblioteca Geral da Universidade de Coimbra se conserva la librería que donó en 1960 el vizconde de Trindade, Alberto Navarro, y que reunía un importante conjunto de opúsculos, relativos, sobre todo, a la Guerra da Restauração (16401668) y a la Inquisición portuguesa; fondos documentales que están asimismo muy presentes en la colección Barbosa Machado. Pero, en el caso de la colección del vizconde de Trindade, fueron adquiridos y encuadernados por este bibliófilo del siglo XX, sin que tengan nada que ver con los gustos y preferencias de un hombre del Antiguo Régimen portugués ${ }^{11}$. Los tomos con los folletos de la colección Barbosa Machado que se encuentran en la Biblioteca Nacional, en Río de Janeiro, fueron asimismo restaurados y encuadernados de nuevo a mediados del siglo XX. No obstante, se procuró respetar la lógica de la composición original ${ }^{12}$.

Al parecer, la transferencia de este conjunto documental al Brasil, dentro de la Biblioteca Real portuguesa, propició que estas partes tan significativas - por su magnitud y por testimoniar una mayor intervención del coleccionador- de la librería de Barbosa Machado, fuesen relativamente preservadas en su integridad física, continuando a ser tratadas como colecciones por bibliotecarios y demás estudiosos. Es decir, a pesar de los errores que se aprecian en las técnicas de restauración empleadas en el pasado, aún hoy es posible visualizar el conjunto de los documentos en su orden y taxonomía originales, expresando la concepción del coleccionador setecentista. El examen interno de las partes o de la totalidad de estos fondos ya ha sido realizado a partir de distintas perspectivas, efectuando sobre todo prospecciones cuantitativas que se han comentado a la luz de la historiografía oportuna. No cabe, por tanto, detallar aquí los perfiles de las llamadas colecciones de retratos y de folletos de Diogo Barbosa Machado ${ }^{13}$.

10 Assunção, G. J. F.: “A Biblioteca volante de Frei Mathias da Conceição”, Separata do Boletim da Junta de Província da Estremadura, 21 (1949). Véase también, del mismo autor, el catálogo mecanografiado en 1965, de 1593 páginas, en la Biblioteca do Palácio Nacional de Mafra.

11 Pericão de Faria, M. G.: “A livraria Visconde da Trindade: esboço da sua história”, Separata do Boletim da Biblioteca da Universidade de Coimbra, XXXIV (1980); Restauração. Catálogo da colecção visconde da Trindade, Coimbra, Biblioteca Geral da Universidade, 1979; y FARIA, M. I. RIBEIRO DE y PERICÃo DE FARIA, M. G.: "Inquisição", Boletim da Biblioteca da Universidade de Coimbra, XXXIII (1977), pp. 235-439.

12 Horch, R. E.: "Catálogo dos folhetos da coleção Barbosa Machado", Anais da Biblioteca Nacional, 92 (1972), 8 tomos. Véase asimismo la entrevista concedida por Rosemarie Horch al autor del artículo en la Universidade de São Paulo, el 20/10/2005, registrada en audio y transcrita.

13 A modo de ejemplo, véase Monteiro, R. Bentes: "Reis, príncipes e varões insignes na coleção Barbosa Machado", Anais de história de além-mar, VI (2005), pp. 215-251; Monteiro, R. Bentes y CaldeIRA, A. P. S.: "A ordem de um tempo: folhetos na coleção Barbosa Machado", Topoi, 14/8 (2007), pp. 77-113; MonTEIRo, R. Bentes y Leite, J. M.: “Os 'manifestos de Portugal'. Reflexões acerca de um Estado moderno”, en ABreu, M. y otros (orgs.): Cultura política e leituras do passado. Historiografia e ensino de história, Río de Janeiro, Civilização Brasileira, 2007, pp. 111-129; MonteIro, R. BEnTES y CARdim, P.: "Seleta de uma sociedade: hierarquias sociais nos documentos compilados por Diogo Barbosa Machado", en Monteiro, R. BEnTES y 
No obstante, dentro de este afán comparativo, cabe llevar el análisis más allá de las clasificaciones formales de los fondos bibliotecarios, que generalmente distinguen entre lo iconográfico y lo escrito, entre lo manuscrito y lo impreso, entre la colección de documentos y la obra de autor publicada ${ }^{14}$. Cuando se superan estas dicotomías que condicionan el estudio, podemos depararnos, por ejemplo, con trabajos como los producidos por João Baptista de Castro (1700-1775), conservados principalmente en la sección de cimélios de la Biblioteca Pública de Évora. Las obras de este oratoriano, de quien se sabe muy poco, pueden compararse con la colección de Barbosa Machado, en la medida en que conjugan lo visual y lo escrito en forma recortada, observando una disposición bastante especial, producto del siglo XVIII portugués. No obstante, es la escritura de mano la que predomina en los libros de Baptista de Castro, con algunos pliegos impresos de mapas y otros recortes. Se trata de obras manuscritas o publicadas sobre vidas de santos y sobre la de Jesús; mapas y libros geográficos de Portugal y España con sus provincias, de Lisboa antes y después del terremoto, sobre otros continentes y, principalmente, sobre el Brasil y Minas; obras de historia secular ${ }^{15}$ y política de Portugal; catálogos de órdenes religiosas y de los reyes portugueses; árboles genealógicos y notas sobre materias diversas, publicados y/o datados entre 1728 y 1771. Varios de los manuscritos examinados dieron origen a libros impresos, aunque algunos ejemplares, por su naturaleza y composición, no parece que se destinasen a su publicación impresa. Salta a la vista la creatividad y la curiosidad del autor, sobre todo en materias geográficas e históricas ${ }^{16}$.

La História geral de Portugal e suas conquistas que compuso Damião António Lemos Faria e Castro (1715-1789) puede asimismo incluirse en esta lista de relaciones, ya que se trata de una de las primeras historias de Portugal, contemporánea a la

otros (orgs.): Raízes do privilégio. Mobilidade social no mundo ibérico do Antigo Regime, Río de Janeiro, Civilização Brasileira, 2011, pp. 69-104.

14 Sobre las formas de comunicación escrita, visual y oral en la Edad Moderna, a menudo coexistentes en un mismo registro, véase BouZA, F.: "Comunicação, conhecimento e memória na Espanha dos séculos XVI e XVII”, Cultura. Revista de história e teoria das ideias. Livros e cultura escrita. Brasil, Portugal e Espanha, XIX (2002), pp. 105-171 [ed. española: Comunicación, conocimiento y memoria en la España de los siglos XVI y XVII, Salamanca, SEMYR, 1999]. Agradezco a Fernando Bouza, Nuno Gonçalo Monteiro y Fernanda Olival, las indicaciones sobre ejemplos susceptibles de comparación para este artículo.

15 Utilizamos en este trabajo el término "secular" apenas para aludir a una dimensión más mundana presente en muchas obras, sin pretender con ello subrayar cualquier ausencia de religiosidad católica o cualquier referencia en torno al rey. Los riesgos de la acepción "secularización", entendida como proceso irremediable y dominante de la Edad Moderna, incluso para el siglo XVIII, son apuntados por MARRAMAO, G.: Poder e secularização. As categorias do tempo [1983], traducción de Guilherme Alberto Gomes de Andrade, São Paulo, Editora Unesp, 1995.

16 Resulta imposible citarlos de forma separada. Su obra más famosa es CAstro, J. B.: Mappa de Portugal, Lisboa, Francisco Luiz Ameno, 1758, cuya idea es comparable al monumental Viaje de España de Antonio Ponz (1725-1792), académico real y también coleccionador de retratos. Véase, RivArA, J. H. C. (org.): Catálogo dos manuscriptos da Bibliotheca Publica Eborense, Lisboa, Imprensa Nacional, 1850-1871, 4 tomos; y DELGADO, D. C.: Un viaje para la Ilustración. El Viaje de España (1772-1794) de Antonio Ponz, Madrid, Marcial Pons, 2012. Manuel Costa informa sobre la correspondencia que, entre 1741 e 1761, mantuvieron Baptista de Castro y Barbosa Machado, ambos nacidos en Lisboa y oratorianos. En la misma, intercambiaban opiniones sobre temas literarios, religiosos y sociales, así como sobre el préstamo de obras personales. CostA, M. A. N.: "Em torno da correspondência de Diogo Barbosa Machado", Separata da Biblioteca da Universidade de Coimbra, 41 (1992), pp. 1-104 у MотA, I. F.: A Academia Real da História. Os intelectuais, o poder cultural e o poder monárquico no séc. XVIII, Coímbra, Minerva, 2003, pp. 189-190. 
elaboración de la colección que examinamos. En el prefacio, Faria e Castro pone de relieve su carácter pionero, al tiempo que alaba las virtudes de la historia ${ }^{17}$. A su juicio, una historia unívoca determina los acontecimientos, aunque los hechos del pasado no dejen de encerrar un contenido moralizante, como enseñanza para las acciones futuras. Para el autor, la historia patria es útil a los eclesiásticos en busca de erudición, a los políticos para el gobierno de los Estados, a los soldados para alentarlos y, sobre todo, a los príncipes "para verem a desigualdade das cores con que ela pinta a virtude, e o vício" ${ }^{18}$. Dada la extensión de la obra, resulta difícil resumir su contenido, aunque, mediante el examen de los sumarios de los veinte tomos publicados y a través de consultas puntuales del texto, es posible analizar la estructura de los temas abordados. En suma, la historia de Faria e Castro comienza con la entrada de los cartagineses en Hispania, pero, desde el tomo III, con la fundación del reino, y hasta el vigésimo, que llega a 1750, la narrativa se ordena en función de las acciones de los sucesivos reyes lusos, unidas a otros hechos. Con la toma de Ceuta en 1415, los sucessos que se relatan -tanto los éxitos como los reveses- pasan a comprender las varias partes del mundo portugués: el reino europeo, África, India y Brasil. Los distintos años permiten, además, vincular estrechamente los asuntos ocurridos en dichos espacios, traduciendo un orden temporal dispuesto según una lógica de progreso. Se aprecia una relativa secularización dentro de la obra, con comentarios sobrios acerca del milagro de Ourique o sobre la desaparición del rey Sebastián en Alcazarquivir. En ambas batallas, el autor menciona a los principales nobles que estuvieron presentes en las mismas. Los gobernadores de los territorios ultramarinos, así como las casas aristocráticas más prominentes, surgen en realidad como una especie de coadyuvantes de las vidas de los reyes, cuyo carácter y virtudes son siempre objeto de comentario al final de cada reinado. Se narran igualmente matrimonios y enredos rocambolescos, como, por ejemplo, el de D. Pedro, $\mathrm{D}^{\mathrm{a}}$. Constanza e Inés de Castro o, de forma más

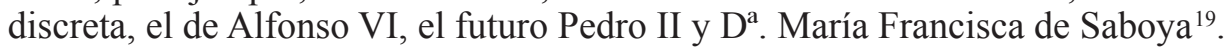

Al final del tomo XVII y al inicio del XVIII, se da cuenta en libros únicos de las vidas y acciones de Felipe I, Felipe II y Felipe III de Portugal, reyes también de España, con un tratamiento más neutro que el otorgado a los demás. El periodo de la Restauração, hasta 1668, aparece ricamente descrito por medio de sus batallas. La deposición de Alfonso VI se trata como si con ella se hubiese puesto "termo à revolta da corte". En el reinado de Pedro II, la coyuntura de la Guerra de Sucesión de España aparece de inmediato evocada, aunque de forma resumida. Llega finalmente el tiem-

17 “...como luz da verdade, que ao mesmo tempo é vida da memória, e mestra da vida. Ela na narração louva, ou condena os conselhos, as ações, os acontecimentos, e as pessoas, como quem pinta com alma, ou fala com vida, para dar consistência às palavras, que voam, e imortalidade às vidas, que acabam. Ela traz à memória os perigos alheios para nos fazer acautelados; a força dos exemplos para nos ensinar a dar uso conveniente a todas as coisas, os altos conselhos, para não tropeçarmos na facilidade, e inconsideração. Ela faz conhecer a causa dos males comuns, e particulares, a dificuldade das empresas, e o modo com que se conseguiram. Enfim, ela une a ciência com a experiência para o racional, que na inconsideração se faz semelhante aos brutos...", Faria e CAstro, D. A. L.: História geral de Portugal e suas conquistas, Lisboa, Typografia Rollandiana, 17861804, 20 tomos. La cita en t. I, p. X. Apenas se sabe que el autor era un hombre rico del Algarve, que estudió con los jesuitas, habiendo sido caballero de la Orden de Cristo e familiar del Santo Oficio.

18 Ibidem, t. I, p. XI.

19 Ibidem, t. I-XVII. 
po de Juan $\mathrm{V}$, de quien se menciona, por ejemplo, la fundación del palacio-convento de Mafra, el matrimonio y la sucesión del príncipe del Brasil, D. José, así como el establecimiento de la Iglesia Patriarcal de Lisboa. La narración continúa hasta la enfermedad del monarca, desde 1742, encerrándose con su muerte y con el elogio de sus virtudes ${ }^{20}$.

Visto desde esta perspectiva, el sumario de la História geral de Portugal e suas conquistas que compuso Faria e Castro no parece muy diferente del orden que impuso Barbosa Machado a la "escritura" de la historia portuguesa por medio de sus colecciones de retratos y folletos. En ellas, los reyes también son protagonistas, secundados por una aristocracia cada vez más cortesana, por los prelados y los gobernadores de los territorios ultramarinos. Se aprecia igualmente una relativa secularización de los temas, aun añadiendo los sermones y los villancicos al extenso conjunto de folletos de historia profana, ya que esos documentos reciben idéntico tratamiento por parte del coleccionador. Una historia que es inclusiva en el tiempo y en el espacio, comprendiendo desde los reyes godos -al menos en los retratos- o el tiempo de la fundación del reino, a los monarcas Habsburgo y los espacios del imperio. En ambas "obras", la coyuntura de la Restauração de la independencia portuguesa aparece especialmente destacada a través de sus batallas. Se concede un peso mayor a los sucesos de la India, a través de las referencias a sus gobernadores, virreyes y cercos militares, que al Brasil, no obstante la América portuguesa pesaba más en la balanza económica de esta monarquía desde el siglo XVII. Como hemos visto, por la forma semejante de los recortes y por los intereses de cuño histórico y geográfico, cabe igualmente la comparación entre los trabajos de Barbosa Machado y los de Baptista de Castro.

En realidad, la perspectiva comparada tiene sentido a fin de captar la idea de historia subyacente a la recopilación de grabados y folletos que llevó a cabo el oratoriano, a la selección realizada y al orden que se le dio, así como al método empleado en su presentación. Bien es cierto que la obtención del material recopilado por compra o por intercambio con otros partícipes de la República de las Letras europea, se vio fuertemente condicionada por la oferta desigual de grabados y opúsculos, mayor para tiempos más cercanos al del propio Diogo Barbosa Machado y más difícil para los retratos e impresos de los siglos XVI y XVII. No obstante, es posible percibir en esta colección una determinada visión del mundo y, por consiguiente, una escritura de la historia propia del conjunto reunido, en relación con varios temas. Cabe señalar que la última comparación que hemos establecido, se ha hecho con respecto a un elemento situado precisamente fuera de aquellos contextos de actuación más familiares para el coleccionista y bibliófilo. Se ha tratado así de evitar el identificar procedimientos comunes -en forma y contenido- con los grupos más conocidos a los que Barbosa Machado estuvo vinculado a lo largo de su vida: la Congregación del Oratorio y la Academia Real da História. Se pretende de este modo superar una perspectiva que suele establecer a priori los paradigmas de elaboración de una obra en función apenas

20 Ibidem, t. XVIII-XX. Existe además un manuscrito sobre el reinado de José I, dedicado a María I; FARIA E CASTro, D. A. L.: História geral de Portugal, e suas conquistas, Academia das Ciências de Lisboa (ACL), Série Azul, Ms. 691. 
de su contextualización social (ejercicio que, no obstante, sigue siendo válido, como veremos más adelante).

Al mismo tiempo, una vez delimitado el objeto, un análisis atento a lo que en él podría vincularse a grupos específicos o a contextos más amplios, abre el camino a una mejor percepción de las heterodoxias y/o innovaciones del propio autor/coleccionista, permitiendo igualmente detectar las posibles continuidades con respecto a sus grupos de origen. Mucho queda aún por hacer en relación con la librería de Barbosa Machado considerada en su conjunto, con el fin de identificar en ella posibles lecturas y afinidades culturales, así como incidentes en la composición de sus colecciones de retratos y folletos ${ }^{21}$. No obstante, una vez realizado el ejercicio de equiparar acervos y obras diversas, cabe prestar también alguna atención a las dos inserciones sociales más conocidas del destacado bibliófilo, dentro del ámbito portugués del siglo XVIII, y a la formación eclesiástica y letrada que le proporcionaron respectivamente. Este análisis se realizará - en la medida de lo posible- teniendo en cuenta aspectos relativos a su trayectoria, a los conjuntos documentales que aquí examinamos y que él estimaba (los folletos y retratos), así como a las transformaciones vividas por la monarquía lusa y por la sociedad de su tiempo.

\section{ORATORIANO}

En la Lisboa de inicios del siglo XVIII, el capitán João Barbosa Machado tenía relaciones sociales entre los círculos medios urbanos, lo que incluía contactos con eclesiásticos, pequeños comerciantes, orfebres y libreros. Entre los mismos, se encontraban los impresores Manuel y António Manescal, propietarios de una tipografía particularmente presente entre los folletos que forman parte de la colección aquí analizada $^{22}$. Este modesto capitán, sin embargo, tuvo tres hijos que ascenderían socialmente a través de la carrera eclesiástica y de las letras. El mayor, José (1674-1750) se hizo enseguida religioso teatino ${ }^{23}$ y se convirtió en orador de prestigio. En 1713, Juan V (1707-1750), después de haberlo oído predicar, lo nombró cronista oficial de la Casa de Braganza. José Barbosa pasó a estar así bajo mecenazgo regio y, a través de

21 Un análisis parcial da librería, aunque sin articulación con la colección de retratos, en SoBraL, L. M.: "The emblem book collection of Diogo Barbosa Machado (1682-1772)", en Gomes, L. (org.): Mosaics of meaning. Studies in Portuguese emblematics, monográfico de Glasgow emblem studies, 13 (2008), pp. 153 187. El catálogo manuscrito de Diogo Barbosa Machado fue transcrito para iniciar el examen de los libros depositados en la Biblioteca Nacional do Brasil; Barbosa Machado: Cathalogo dos livros... op. cit. (nota 2).

22 Entre los 3185 folletos que componen la colección analizada, el taller de los Manescal es el segundo que mayor presencia tiene, con 233 folletos impresos que salieron de sus prensas, sobre todo villancicos cantados en la capilla real en el siglo XVII. Cabe preguntarse si este vínculo familiar de los Barbosa Machado habría facilitado el acceso a los opúsculos de una época anterior.

23 Para Isabel Mota, el fondo de los teatinos portugueses en la Biblioteca Nacional de Portugal muestra la existencia, en la primera mitad del siglo XVIII, de un grupo de trabajo dedicado a la erudición y la crítica muy sofisticado y estructurado. La búsqueda de fuentes, la crítica bibliográfica, el rigor en la escritura que llevó a cabo este grupo de personas de forma sistemática, envolvía también a sus secretarios, siendo prueba cabal de un nuevo perfil de hombre de letras, con vínculos internacionales y próximo a las esferas del poder. En esta "sociedad intelectual", destacarían António Caetano de Sousa, Manuel Caetano de Sousa, D. José Barbosa y otros. МотА, op. cit. (nota 16), p. 68. 
él, entró a formar parte del grupo de letrados del conde de Ericeira y, más tarde, de la Academia Real da História, quedando eximido de ocupar cargos dentro de su orden religiosa. Compuso entonces varias obras, adquirió muchos libros y fue examinador de las órdenes militares (Cristo, Avís y Santiago) y del Patriarcado de Lisboa (cargos que obtuvo dentro de sus círculos clientelares). Entre los tomos que componen la colección de folletos analizada, hay dos dedicados a los sermones proferidos por el padre José Barbosa. Por su parte, el hijo más joven de João Barbosa Machado, Inácio (1686-1766), tras estudiar filosofía en la Congregación del Oratorio y defender conclusiones públicas, se formó en derecho por la Universidad de Coímbra. Posteriormente, fue magistrado en Bahía y miembro de las academias literarias de los Esquecidos y de los Renascidos, en la misma ciudad de Salvador, que entonces era la capital del Estado del Brasil. En 1734, viudo, se hizo clérigo oratoriano. Fue también magistrado de la Relação de Oporto y, en su calidad de miembro de la Academia Real da História Portuguesa, fue cronista general de los territorios ultramarinos. Al morir, dejó una biblioteca de más de 2000 volúmenes, aneja a la de su hermano Diogo, ya que ambos hermanos vivían en la misma casa.

El segundo de los hijos, Diogo Barbosa Machado, realizó sus primeros estudios en Lisboa. Después se trasladó a Coímbra, donde se matriculó en la Facultad de Derecho Canónico. Con todo, no prosiguió su formación universitaria y regresó a la capital, recibiendo en 1724 las órdenes como presbítero dentro de la Congregación del Oratorio. En 1728, el marqués de Abrantes, hombre de poder en los círculos cortesanos lisboetas, consiguió que lo nombrasen abad de Santo Adrião de Sever (obispado de Oporto), de cuyas tierras era donatario. Este beneficio le permitió contar con mayores rentas, si bien nunca quiso permanecer en la distante y modesta iglesia del norte del país. Enseguida presentó a su protector la renuncia, que le fue concedida con una pensión suficiente para comprar libros y no salir más de Lisboa, pudiendo así dedicarse a las letras y a la historia ${ }^{24}$.

Los archivos de la primera casa que tuvo en Lisboa la Congregación del Oratorio, se perdieron con el terremoto de 1755 . Esto nos obliga a tener que dar por supuesta la formación oratoriana de Barbosa Machado si queremos establecer vínculos con su trayectoria y sus realizaciones. En el siglo XVI, Ignacio de Loyola y Felipe Neri ${ }^{25}$

24 Conservó el prestigioso capelo abacial con borlas en sus armas, en su ex-libris, en sus retratos grabados presentes en la Bibliotheca Lusitana y en el álbum de varões insignes em letras, artes e ciências de su colección de retratos, continuando a ser tratado como tal. Ibidem, pp. 226-232; Galvão, B. F. R.: "Diogo Barbosa Machado", Anais da Biblioteca Nacional, 92 (1972), t. 1, pp. 11-45.

25 El florentino Felipe Neri (1515-1595), tras una juventud discreta, se ordenó sacerdote en 1551. En Roma reunió amigos con el fin de cuidar de enfermos, pobres y peregrinos. La biografía de san Juan de Dios le impresionó, mandándola traducir al toscano. En ella, se narraban las obras del fundador de un hospital para enfermos incurables. Los sacerdotes del grupo de Neri proponían modelos de acción a los peregrinos, orando con ellos cerca de la Iglesia de San Jerónimo de la Caridad. El lugar pasó a ser conocido como "Oratorio". Desde 1564, se organizó ahí una comunidad de clérigos y seglares conforme a los ideales de Neri, actuando en libertad. Felipe Neri recibió el encargo de la iglesia de San Juan de los Florentinos, consolidado como núcleo en el que se practicaba la lectura, la meditación, los diálogos, los sermones improvisados y los cánticos. Se realizaban asimismo obras de socorro a pobres, enfermos, presos y peregrinos. Eran sacerdotes sujetos a la obediencia a los obispos y movilizados para el servicio de los fieles. En 1575, Gregorio XIII hizo del Oratorio una congregación secular, cuya regla fue adoptada en 1583 y modificada en 1588 y en 1595 , tras la muerte de Felipe. Los estatutos fueron aprobados por el papa en 1612, creando un grupo eclesiástico propio: sus 
se conocieron en Roma. Neri frecuentaba los espacios jesuitas, admiraba su organización y apreciaba los primeros frutos de su actividad misionera por el mundo. Pero su sensibilidad era intuitiva y ajena a preceptos rígidos ${ }^{26}$. La comunidad creada por Neri en Roma vivía sin reglas fijas, persiguiendo una vía intermedia, ni regular, ni totalmente civil o mundana, sin votos perpetuos o renuncia de bienes. Tras la muerte de Neri, las biografías en torno a su figura circularon en latín, italiano o castellano, favoreciendo la creación de nuevas casas. Con este espíritu independiente y original, la Congregación del Oratorio floreció en Italia, España, Portugal y Francia (en este país de forma más centralizada). Los modelos de estos varios espacios se extendieron después a los espacios de Asia y América ${ }^{27}$.

Durante la Unión de Coronas, la vida y la obra de Felipe Neri tuvieron una considerable recepción en España y en Portugal. Las biografías traducidas o escritas en castellano afirmaban que el clérigo florentino privaba con altas figuras públicas españolas, apreciaba a sus santos y sus autores espirituales, así como su música sacra. En 1622, Felipe IV envió una embajada a Roma con ocasión de la canonización de los españoles Ignacio de Loyola, Francisco Javier y Teresa de Jesús, que coincidió con la de Felipe Neri. En Lisboa, había una congregación de sacerdotes que se reunía bajo su advocación. En 1664, en Oporto, se le dedicó una capilla y, más tarde, surgió un grupo de seculares, vinculados por medio de la oración pública y mental, los sacramentos y las confesiones frecuentes. Desde mediados del siglo XVII, san Felipe Neri despertaba cada vez mayor devoción entre clérigos y seglares, hombres y mujeres.

Con todo, el surgimiento del Oratorio portugués se debió a Bartolomeu de Quen$\operatorname{tal}^{28}$, predicador en la corte de Juan IV (1640-1656) y protegido de la reina Luisa

miembros no profesaban votos, mantenían sus bienes y podían abandonar la institución; los que ingresasen tendrían que sustentarse por sí mismos o ser adoptados por alguien; se dedicarían a la piedad pública (ejercicios espirituales, predicación, meditación, caridad, confesiones y enseñanza) destinada a los propios miembros y al exterior. En cada casa había una jerarquía que rotaba entre los miembros, que obedecían a la autoridad del Ordinario local. Felipe Neri fue beatificado en 1612 y santificado en 1622. SANTOS, E.: "Oratorianos", en Franco, J. E. (org.): Dicionário histórico das ordens. Institutos religiosos e outras formas de vida consagrada católica em Portugal, Lisboa, Gradiva, 2010, pp. 232-233.

26 En el derecho canónico, oratorio es un lugar de culto divino, distinto de la iglesia, que es sagrada. El oratorio, sea público o particular, se diferencia también de la hermandad al no requerir filiación de los participantes, pago de anualidades y no ofrecer ayuda financiera para misas, sepultura y otros auxilios. A finales del siglo XV surgió el Oratorio del Amor Divino, siendo un nuevo modelo de asociación voluntaria en el que las actividades se alargaban al exterior, poniendo particular énfasis en la caridad. Tal vez este modelo tuvo influencia sobre Felipe Neri al crear su congregación. IshaQ, V. F. S.: Catolicismo e luzes. A Congregação do Oratório no mundo português, séculos XVI-XVIII (tesis de doctorado en Historia Social), Niterói, Universidade Federal Fluminense, 2004, pp. 23-26.

27 Sobre estas cuestiones, SANTOS, op. cit. (nota 25), pp. 231-239.

28 Nacido en Azores, Bartolomeu de Quental (1626-1698) procedía de un grupo intermedio ennoblecido, educado en el modelo tridentino. Se trasladó a Portugal a los 16 años, estudió filosofía en Évora como alumno de los jesuitas, doctorándose en 1648. Cursó teología en la misma universidad y tres años más tarde, se trasladó a Coímbra, donde recibió órdenes sacras en 1652. Aunque António Vieira era entonces el orador por excelencia, Bartolomeu de Quental también ganó fama. El joven presbítero se lanzó a la acción pastoral, urbana y rural, continuando a frecuentar la iglesia de los jesuitas. Juan IV lo nombró, en 1654, capellán confesor y predicador extranumerario de la corte. Organizó así un núcleo piadoso regular y dirigido, en el que el énfasis se ponía en la oración mental. Durante cinco años actuó en la corte brigantina y en las parroquias de Lisboa. Sin embargo, las luchas intestinas y el ambiente pesado tras la muerte de Juan IV le hicieron dedicarse más a las misiones. En 1659, instituyó una congregación de sacerdotes con autorización papal. 
de Guzmán. Entre 1664 y 1667, ante la crisis que enfrentó al infante D. Pedro con Alfonso VI (1656-1683) por la disputa del trono, Quental estaba entre los predicadores que habrían de denunciar el carácter impropio del gobierno del rey, al frente del cual se encontraba el conde de Castelo Melhor, escrivão da puridade ${ }^{29}$. A pesar de la victoria de D. Pedro (a partir de entonces príncipe regente), decidió abandonar el núcleo de oración y las actividades que realizaba en la corte de los Braganza, para seguir vida de alguna clausura y desarrollar un proyecto misionero. Nacía así, en 1668, la Congregación del Oratorio de Portugal, coincidiendo con el reconocimiento de la independencia lusa por España y en un tiempo de enorme prestigio de la Compañía de Jesús. Aunque los oratorianos estaban igualmente orientados a la evangelización social, eran contrarios a los votos perpetuos ${ }^{30}$.

El nuevo Oratorio portugués era por tanto una asociación de clérigos seculares, libres de votos, dinámicos, cultos, ejemplares y sujetos a la jerarquía eclesiástica local. Quental se inspiró en las reglas del Oratorio romano y en las del francés. Prefería la independencia de las comunidades, aunque con un prelado superior interno, elegido en asamblea y que representase a cada casa: un "general". En 1672, el papa reconoció sus estatutos, con un apéndice aprobado en 1693. Este espíritu original, con todo, daría lugar a prácticas diversas. Tras la muerte de Quental, ningún otro general o visitador dispondría de la misma autoridad. Además de las dos casas lisboetas (la primera en el Chiado y una segunda en Necessidades, desde mediados del siglo XVIII), hubo otras en Freixo-de-Espada-à-Cinta, Oporto, Braga, Viseu y Estremoz, fruto del impulso generador -sobre todo en el norte del país- que se produjo durante la segunda mitad del siglo XVII ${ }^{31}$. Hubo además casas oratorianas en Pernambuco (Brasil) y en Goa, en la India portuguesa. Cada casa alojaba tres tipos de personas: los novicios o pretendientes por un año, que vestían hábito pardo o gris; los hermanos admitidos, que vestían de negro; los estudiantes internos o externos. Los cargos previstos en los estatutos se dividían entre estos tres grupos, aunque algunos se destinaban apenas a una categoría de miembros. Para determinadas tareas, se recurría a asalariados externos. El ritmo de vida era común (levantarse, acostarse, comer, etc.), pero había tareas específicas (estudio público, predicación, misiones, visitas a cárceles y hospitales). Los hermanos sacerdotes tenían un cotidiano más flexible, apenas sujeto a las obligaciones conjuntas de despertarse, comer, rezar y acostarse. La propia iniciativa les permitía ocuparse en actividades para las que eran elegidos cada tres años o centrarse en la ciencia, la jurisprudencia, la enseñanza o la preparación de textos.

Los que adhirieron a la misma se juntaban en una dependencia de la capilla real concedida por $\mathrm{D}^{\mathrm{a}}$. Luisa de Guzmán, transformada en oratorio. Ibidem, pp. 234-236.

29 Sobre la importancia de la parenética en el período de la Restauração en Portugal, MARQues, J. F.: A parenética portuguesa e a Restauração 1640-1668. A revolta e a mentalidade, Oporto, Instituto Nacional de Investigação Científica, 1989, 2 vols.

30 Oratorianos, jesuitas, vicentinos, franciscanos y capuchinos eran los grupos religiosos más activos en las misiones de interior en la Europa católica, como parte de sus tareas de disciplinamiento confesional. Palomo, F.: A Contra-Reforma em Portugal, 1540-1700, Lisboa, Horizonte, 2006, p. 81.

31 Estas han sido analizadas, gracias a la existencia de registros, por SANTos, E.: O Oratório no norte de Portugal. Contribuição para o estudo da história religiosa e social, Oporto, Instituto Nacional de Investigação Científica, 1982. 
Para Eugénio dos Santos, entre finales del siglo XVII y la primera mitad del XVIII, el Oratorio portugués contribuyó a afirmar un nuevo modelo de clérigo: culto, riguroso, abierto a los fieles, desinteresado por los beneficios temporales y en sintonía con los nuevos rumbos de la ciencia. Esto les valió el respeto y el apoyo de la elite cultural portuguesa. En 1717, Juan V permitió que los alumnos de los oratorianos entrasen directamente en la Universidad, lo que, hasta entonces, apenas se había concedido a los jesuitas del Colegio de las Artes. El privilegio fue revocado en 1724, pero se retomó al año siguiente, extendiéndose a las demás órdenes en 1755. En aquel reinado, era notorio el prestigio de que gozaba la institución, sobre todo la casa de Lisboa; en definitiva, el ambiente que rodeó a Diogo Barbosa Machado cuando formó su librería y sus colecciones.

Se conoce apenas el contenido de las bibliotecas oratorianas de algunas de las casas del norte de Portugal, que ponen de manifiesto su apertura a las nuevas corrientes filosóficas, científicas y pedagógicas, permitiendo entender la preferencia que mostraron algunos alumnos por sus escuelas públicas ${ }^{32}$. Al principio, el Oratorio portugués no previó la organización de estudios regulares abiertos a jóvenes, tanto internos como externos, dado el prestigio que entonces tenía el edificio pedagógico jesuítico. Bartolomeu de Quental poco a poco aceptó la necesidad de organizar estudios propios, aunque trató de evitar el competir con las órdenes religiosas existentes. La apertura a determinadas influencias pedagógicas, inspiradas en la Francia del siglo XVII, incluiría la aceptación de la ciencia experimental, con gabinetes de observación y replicación, las disciplinas de matemática y de lógica, y la colección de materiales de varios tipos y procedencias. Todo ello despertaría la curiosidad de las nuevas elites cultas y ayudaría a construir una reputación nueva en torno a los oratorianos que haría de ellos la vanguardia, tanto en métodos como en contenidos ${ }^{33}$, influyendo probablemente en los trabajos de Luís António Verney, el estrangeirado, nacido en Lisboa y radicado en Roma $^{34}$.

32 Por informaciones provenientes de sus miembros, la casa lisboeta, destruida en 1755, abrigaba a sujetos eruditos e influyentes, con una de las más selectas bibliotecas privadas de Lisboa en el siglo XVIII, tipografía y equipamiento científico sin parangón en cualquier casa de la Congregación, favorecida por las academias literarias y científicas que estaban bajo protección regia en la capital portuguesa. Ibidem, pp. 308 y 321.

33 Desde 1737, era conocida la ruptura de los miembros de la Congregación con la filosofía natural discutida en Coímbra y con la Segunda Escolástica, acentuándose en las décadas siguientes. El oratoriano João Baptista (homónimo al anterior João Baptista de Castro, cuyas obras denotan particular aprecio por la corografía) destacó dentro de esta renovación cultural, dominando la bibliografía filosófica y científica producida fuera del ámbito escolástico, pero manteniendo la orientación aristotélica en la enseñanza de la lógica. En el campo de la física, se produjeron algunas modificaciones por influencia del oratoriano español Vicente Tosca, que llevó al padre João Baptista a defender la enseñanza de la matemática para el estudio de la materia. En la nueva casa de Necessidades, en Lisboa, tras el terremoto, los oratorianos modificaron los estudios de las escuelas de la Congregación, incluyendo la geografía y nuevas directrices para los estudios de historia y latín. Esta casa poseía biblioteca y gabinete de física experimental, y tenían una renta de 220 mil réis anuales para actividades de edición. El gabinete, con aparatos y tipografía propios, ayudó a consolidar la reputación de la Congregación del Oratorio como institución propagadora de un pensamiento moderno. IsHAQ, op. cit. (nota 26), pp. 276-277 y 284-285; SANTOS, op. cit. (nota 31), p. 309.

34 Verney cuestionó la cultura y la filosofía tradicionales en Portugal, sobre todo la enseñanza jesuita. Entre las escuelas portuguesas, el Oratorio sería la institución más abierta a su propuesta de reforma de la enseñanza. IsHaQ, op. cit. (nota 26), pp. 286-302. Con todo, el ilustrado luso desdeñó los métodos empleados por Diogo Barbosa Machado en la Bibliotheca Lusitana. Costa, op. cit. (nota 16). 
No obstante, la Congregación del Oratorio hubo de enfrentar problemas durante el gobierno de Sebastião José de Carvalho e Melo, el futuro marqués de Pombal y entonces valido de José I (1750-1777), cuando se produjeron los destierros del P. Teodoro de Almeida y de otros correligionarios. Las razones de estas persecuciones no están claras, pero hay una de orden circunstancial y de naturaleza política, que tiene que ver con una posible represalia del secretario de Estado frente a la censura que hicieron los oratorianos y el hermanastro del rey, el inquisidor general, a un libro de tenor regalista, defensor del poder regio en los dominios reservados al foro eclesiástico. El escrito habría estado inspirado por el propio Carvalho e Melo y no obtuvo el beneplácito de los censores oratorianos, sobre todo de João Baptista y de Teodoro de Almeida, poco antes de que se creara la Real Mesa Censória, en $1768^{35}$.

Sebastião José tenía un poderoso aliado oratoriano en la figura del P. António Pereira de Figueiredo. Durante su gobierno, de hecho, la Congregación se escindió. El ministro propuso al monarca extinguirla, llegando a redactar un decreto a este respecto que acabó por no llevarse a efecto. Los oratorianos, con todo, soportaron distintas violencias durante el periodo, viendo lugares de culto cerrados, la prohibición de entrada de novicios e impedimentos en la renovación de sus gobiernos (lo que significaba incumplir sus estatutos). Las justificaciones públicas eran múltiples, desde el trato irrespetuoso de los maestros oratorianos a los hijos del rey, a los vínculos estrechos de los religiosos con la alta nobleza, proscrita tras el atentado contra José I, atribuido a los Távora, o algunas de las creencias de los clérigos, como el culto a reliquias a las que se atribuían poderes ${ }^{36}$. En 1759 , además, se expulsó a los jesuitas de Portugal y de sus dominios y la situación político-institucional se hizo más tensa, ya que los ignacianos tenían influencia entre la nobleza tradicional.

En este sentido, conviene relativizar la aparente oposición entre jesuitas y oratorianos, potenciada por la delicada coyuntura del siglo XVIII. Como hemos visto, varios padres congregados se formaron en la Compañía y, dentro de las propias colecciones de Barbosa Machado, no encontramos elementos despectivos entre ambos grupos. En los retratos, los jesuitas, eximios comunicadores y propagandistas de su memoria, aparecen profusamente a través de sus mayores exponentes o mediante la representación de naufragios sufridos a manos de herejes o de piratas. En los folletos, hay muchos sermones impresos proferidos por António Vieira y por otros religiosos de la Compañía, siendo escasas las referencias a la persecución que ésta sufrió durante el reinado de José I (como señalábamos, el opúsculo más reciente es de 1770). En relación con los varones insignes vinculados al Oratorio o simpatizantes del mismo, Bartolomeu de Quental figura en siete retratos, Manuel Bernardes en dos, Verney en uno, el propio Barbosa Machado en dos y su hermano Inácio en uno ${ }^{37}$. Todos figuran en el tomo relativo a los varones ilustres en letras, artes y ciencias, lo que pone de mani-

35 A comienzos de la década de 1760 , estaba vigente en Portugal un sistema de censura que requería las autorizaciones del Desembargo do Paço, la Inquisición y el ordinario para publicar una obra. MARTINs, M. T. E. P.: A censura literária em Portugal nos séculos XVII e XVIII, Lisboa, Fundação Calouste Gulbenkian, 2005.

36 SANTOS, op. cit. (nota 31), pp. 231-234.

37 El retrato de Inácio Barbosa Machado fue robado en Portugal, antes de que la colección se trasladase a Río de Janeiro, como señala el bibliotecario de la corte. Cfr. MARrocos, L. S.: Noticia sobre a collecção dos retratos de Diogo Barboza Machado, Biblioteca da Ajuda (BA), Ms. 52-XIV-35 94, fol. 12 v. 
fiesto la identidad erudita que distinguiría al grupo, representado en medio de libros, estantes, papeles y plumas. Cabe señalar, además, la presencia de 17 retratos de quien fuera la inspiración primera de Felipe Neri, san Juan de Dios, personaje que tenía una mayor presencia en el tomo relativo a los varones insignes en virtudes y dignidades ${ }^{38}$. No obstante las características innovadoras de la Congregación portuguesa en el siglo XVIII, el perfil del conjunto documental que elaboró Barbosa Machado está claramente orientado hacia el pasado, sin conexiones científicas o experimentales, a no ser por la presencia de algunos retratados que actuaban en dichas esferas. Resta, por consiguiente, examinar el otro ámbito de actuación de nuestro coleccionador.

\section{ACADÉMICO REAL}

La actuación de Diogo Barbosa Machado en la Academia Real da História Portuguesa desde 1720, como uno de sus cincuenta miembros fundadores, es más conocida $^{39}$. Probablemente entró en ella bajo el patrocinio del marqués de Abrantes, uno de los primeros censores académicos, con interés por la historia, la arquitectura y la pintura. La Academia Real da História surgió al hilo de las academias literarias que hubo en Portugal desde el siglo XVII, sobre todo de grupos liderados por los condes de Ericeira, de carácter más particular y cortesano. Estuvo asimismo inspirada en los círculos académicos europeos y, en especial, en el ejemplo italiano y en el francés, desarrollado al amparo de Luis XIV ${ }^{40}$. La experiencia portuguesa, con todo, tendría dos especificidades: la historia como campo fundamental de estudios y la inclusión de las conquistas ultramarinas lusas en los procesos de recopilación de información y de elaboración de obras dentro de la Academia. Se sustituyó así a los viejos cronistas regios y religiosos por nuevos académicos reales, sujetos por vínculos clientelares a la alta nobleza y/o al mecenazgo creciente del monarca, cuyo objetivo era el de promover una nueva historia profana y eclesiástica del reino y de sus conquistas en África, América y Asia. Esa historia podía traducirse -no sería raro- en una suma de memorias y el tono panegírico, además, no estaría ausente de muchos trabajos, a pesar de que, al mismo tiempo, se buscase una perspectiva crítica.

Estos aspectos no dejarían de estar presentes en la Bibliotheca Lusitana, concebida como un diccionario de memorias de escritores portugueses de todos los tiempos, valorados retrospectivamente en función del ambiente académico entonces dominante,

38 Juan de Dios (1495-1550) nació en Montemor, Portugal, trasladándose después a Granada, donde se le habría aparecido el niño Jesús. Destacó por su labor de socorro a los enfermos y su vida fue relatada en varias lenguas. Fue canonizado en 1690.

39 Al respecto, véase Мота, op. cit. (nota 16).

40 La institucionalización académica en Portugal fue distinta de la que tuvo lugar en España, donde el perfil de la Real Academia de la Historia, creada en 1738, era más cortesano y enciclopédico, con el proyecto de un gran diccionario crítico e histórico del país. El modelo español se aproximaba más del inglés. En ambos casos había protección regia, pero los privilegios de censura y financiación variaban, dependiendo de negociaciones con los monarcas. La fundación de la Real Academia tampoco significó la inmediata incorporación de los cronistas regios y de Indias, como sucedió en Portugal. KANTOR, I.: Esquecidos e Renascidos. Historiografia acadêmica luso-americana (1724-1759), São Paulo/Salvador, Hucitec/Centro de Estudos Baianos - UFBA, 2004, pp. 39-40, y Moreno, E. V.: La Real Academia de la Historia en el siglo XVIII, Madrid, CEPC, 2000. 
como signo de la promoción social de los nuevos letrados, a pesar de su dependencia de poderes superiores. También estarían presentes en la obra encomendada a Barbosa Machado sobre las memorias del rey Sebastián (1554-1578), publicada en cuatro tomos por los impresores de la Academia y dedicada a Juan $\mathrm{V}^{41}$. En el prólogo, el autor hace referencia a la consulta de los documentos disponibles (crónicas, cartas, testamentos, noticias, archivos diversos, etc.), así como al método empleado, preocupado por mostrarse neutro frente a las creencias sebastianistas y a la tragedia de Alcazarquivir. Esta postura era la que distinguía al poeta - con libertad para huir de todo- del historiador, fiel narrador de las acciones pasadas, obligado a fundar sus escritos sobre bases sólidas. Con "estilo claro", aunque "ornado de alguma pompa onde a materia fosse digna de maior decoro", el académico exponía así los argumentos de unos y otros en defensa de la muerte del rey o de su supervivencia; aludía a la opinión de que D. Sebastián estaba vivo, surgida ya en tiempos del cardenal-rey D. Enrique; hacía referencia a los falsos Sebastianes; comentaba cómo, violentamente, Felipe II se había hecho señor de Portugal ${ }^{42}$. En el texto siguiente, elogiaba la paz del imperio luso frente a los tumultos europeos de entonces, y aludía al triste destino de este príncipe como si se tratase de un capricho de la fortuna. Y, del mismo modo que el cosmógrafo era capaz de reducir el extenso mundo a un mapa, también él había de narrar las acciones memorables ocurridas en las "quatro partes do universo", pues ellas conformaban asimismo "o corpo desta História"43. Discurría así por las distintas plazas que Portugal tenía en África, América y Asia, así como por los personajes de la corte, las reinas, las princesas y los "varones insignes" 44 .

Con todo, esta historia era en buena medida un compendio de memorias de distintos personajes, años y espacios. En 1721, en las normas relativas a las disposiciones textuales sobre la historia secular de la Academia, se recomendaba contar la historia del estado en el que se encontraba el reino en aquel tiempo, así como la vida del rey en sus detalles, con copias de retratos existentes. La narrativa debía proseguir con la aclamación, los matrimonios, los nacimientos y con la noticias de los varones insignes en armas, política y letras, igualmente ornados con estampas. La periodización

41 Barbosa Machado, D.: Memórias para a história de Portugal que compreendem o governo de El Rei D. Sebastião, Lisboa, Officina de Joseph Antonio da Silva/Regia Officina Sylviana, 1736-1737 (tt. I y II) y $1747-$ 1751 (tt. III y IV). El primer impresor de la Academia Real fue Pascoal da Silva, que acumuló estas funciones a las de impresor regio. Más tarde, su hijo, José Antonio da Silva, asumió la dirección de la imprenta. En torno a 1738, pasó a designarse Officina Sylviana, apareciendo también como Regia Officina Sylviana. El cuidado técnico de las producciones pone de manifiesto su cualidad superior. MotA, op. cit. (nota 16), p. 90. En la colección de Barbosa Machado, la tipografía Sylviana fue responsable de la impresión de 194 folletos.

42 Barbosa Machado, op. cit. (nota 41), t. 1, sin paginar.

43 Ibidem, p. IV.

44 Ibidem, pp. IV-XV. Había puntos delicados de la historia portuguesa que debían ser preservados, como el milagro y la vida sin mancha de pecado de Alfonso Henriques (1109-1185), convenientes en un rey al que se quería canonizar como fundador de la monarquía lusa; las actas de las cortes de Lamego, forjadas en Alcobaça, que regulaban una hipotética sucesión del reino en el siglo XII; o la primacía de la catedral de Braga desde los tiempos de la guerra contra los musulmanes. Episodios que ponían en duda la legitimidad de la independencia lusa frente a Castilla y que debían ser tratados como verdaderos. MotA, op. cit. (nota 16), p. 72. Los historiadores regios estaban abiertos a la incorporación de los métodos críticos, pero se mantenían distantes con respecto a posiciones que podían ensombrecer la gloria patria y la unidad política del reino. KANTOR, op. cit. (nota 40), p. 80. 
estaría determinada por la sucesión de los reinados, cada uno de los cuales debía tratarse en cuatro partes: una primera dedicada a los orígenes de la monarquía y de la nobleza, una segunda sobre el gobierno civil, otra acerca de los aspectos militares y una última referente a los descubrimientos y conquistas realizadas, sugiriendo que se comenzase por el continente africano - con arreglo a un principio de contigüidad geográfica-y se terminase con las conquistas asiáticas ${ }^{45}$.

Se debían narrar las expediciones terrestres y marítimas, y exponer la justificación de las guerras, la forma de las milicias, las batallas, las plazas sitiadas, los socorros de los aliados y las acciones de los gobernadores, sin olvidar las acciones "fora da pátria" de "homens ilustres" nacidos en Portugal. Los académicos intentaban registrar los hechos gloriosos de los portugueses, incluso a favor de otros príncipes. En el caso de los territorios coloniales, el conocimiento era fragmentario, ya que sus instituciones eran diversas y geográficamente dispersas, siendo numerosas las dificultades para recopilar las informaciones ${ }^{46}$. Para Íris Kantor, surgiría entonces una nueva razón de Estado, más secular con respecto a los principios político-teológicos que en el pasado habían respaldado la expansión lusa. La necesaria preservación de las rutas comerciales entre el Índico y el Atlántico y el descubrimiento de oro en el Brasil exigían una acción más articulada de la Corona para, después del tratado de Utrecht y antes del de Madrid, defender su soberanía en América. Se ponía de manifiesto una nueva percepción territorial que se traduciría en una visión de conjunto sobre la geografía y la historia del reino y de sus dominios ${ }^{47}$.

Estas características se encuentran en los folletos y retratos recopilados por Diogo Barbosa Machado. Los opúsculos incluyen odas, oraciones, églogas, panegíricos, sermones y elogios varios (proferidos, sobre todo, por miembros de la Academia Real ${ }^{48}$, pero también tratados internacionales, autos de cortes, relatos de embajadas, de batallas, etc. Si la interpretación en torno al modo de escribir la historia de Portugal y de sus conquistas que subyace en la colección, sólo tiene sentido cuando la consideramos en su conjunto, lo mismo cabe decir en relación con otras obras académicas aquí analizadas, así como para la historia de Damião Faria e Castro, elaborada

\footnotetext{
45 "Systema da historia ecclesiastica, e secular de Portugal, que ha de escrever a Academia Real da Historia Portuguesa", Collecçam dos documentos, estatutos, e memorias da Academia Real da Historia Portugueza, Lisboa, Pascoal da Silva, 1721, apud Mota, op. cit. (nota 16), pp. 58-60, y KanTor, op. cit. (nota 40), p. 57.

46 Ibidem, pp. 57-58. Según Diogo Barbosa Machado en el aniversario de María Ana de Austria, los portugueses, en el futuro, también participarían de esta gloria, al hallar en los hechos valerosos de sus antepasados ejemplos de amor a la patria, celo y fidelidad, para imitarlos. "Panegírico de Diogo Barbosa Machado em conferência de 7 de setembro, no Paço, dia do aniversário da Rainha", Collecçam dos documentos (1722), apud KanTOR, op. cit. (nota 40), p. 58.

47 Ibidem, pp. 45-57 y KANTOR, "A Academia Real de História Portuguesa e a defesa do patrimônio ultramarino: da paz de Westfália ao Tratado de Madri (1648-1750)", en Bicalho, M. F. y Ferlini, V. L. A. (orgs.): Modos de governar. Idéias e práticas políticas no império português. Séculos XVI a XIX, São Paulo, Alameda, 2005, pp. 257-276.

48 En la década de 1730, la Academia se haría más presente en las ceremonias de glorificación de la monarquía, en un momento en el que la Colecçam dos documentos ya apenas se componía de elogios fúnebres, discursos de entradas de académicos y oraciones panegíricas; folletos venales que despertaban el interés del público. La gran mayoría de esas piezas fue presentada en el palacio de la Ribeira, en conferencia pública. Se procedió así a publicar impreso lo que se consideraba más importante o comercial: la exaltación del rey y de sus académicos. MotA, op. cit. (nota 16), p. 276.
} 
a partir de múltiples fragmentos narrativos, ordenados en función de los reyes, los años y los continentes, con arreglo a la pauta establecida por el historiador.

A la hora de encuadernar sus opúsculos, Barbosa Machado usó criterios relacionados con los géneros literarios, la naturaleza del episodio (panegíricos, entradas, exequias, etc.) y el personaje central del documento (reyes, princesas, grandes de Portugal, etc.), recurriendo igualmente a la clasificación sexual. A continuación, se valió de la cronología para dividir los tomos: "de 1640 a 1668", de "1669 a 1706", "no ano de $1750 " .$. La cuestión espacial también sirvió para identificar tomos dedicados a sucesos de Asia, América o África. Parece que hubiese reunido primero todo el conjunto documental o su mayor parte, para, después, mandarlo encuadernar. Otro aspecto tiene que ver con la disposición de los tomos en su catálogo manuscrito, que permite identificar algunos de sus criterios más relevantes. Con arreglo a este orden, en la "historia profana", los reyes y príncipes aparecen en primer lugar, como en los retratos. Nacen (genetlíacos), cumplen años, "entran" -o dominan- la capital del reino, se casan (epitalamios), enferman (oraciones por la salud de Juan V) y mueren (exequias). A continuación, surgen los aspectos militares (el corpus mayor, con 521 documentos), agrupados por reinados. A este respecto, cabe subrayar la postura compiladora que se aprecia a la hora de incorporar traumas ya superados en la historia de Portugal a mediados del siglo XVIII. Así, en relación con la guerra de independencia portuguesa y con la de Sucesión española, se incorporan documentos castellanos en contra de Portugal. Los hechos de guerra, por lo demás, se extienden a los territorios ultramarinos. La literatura militar no enaltecía apenas a los reyes, sino también a los bravos portugueses, nobles y plebeyos ${ }^{49}$.

Este es el puente con el mundo aristocrático, agrupado igualmente siguiendo el ciclo de vida: nacimientos, matrimonios, muertes. Se prosigue con los folletos relativos a los clérigos. Los panfletos y libelos políticos ("manifestos de Portugal"), los tratados y autos de cortes, aparecen mezclados con este bloque, antes de las noticias genealógicas de la casa real y de las casas de la nobleza. Por su parte, las misiones de Oriente y las procesiones abren el camino a la documentación de carácter religioso. Dentro de la historia eclesiástica, el orden que se da a los sermones comienza también con los temas relativos a los reyes y, en primer lugar, los proferidos por José Barbosa, cronista oficial de los Braganza. A continuación, los relacionados con la Restauração y con la aclamación de Juan IV, así como los sermones proferidos con ocasión de los nacimientos, matrimonios y muertes, primeramente de los reyes y, después, de los nobles y eclesiásticos portugueses. Se finaliza la colección con los sermones pronunciados en autos de fe y con los villancicos ${ }^{50}$.

En la colección de retratos, algunos personajes nacidos en Portugal, pero que actuaron en el extranjero, contarían con grabados recortados, como Isabel de Portugal, mujer de Carlos V, que aparece en 16 ocasiones, o el navegante Fernando de Magallanes, que lo hace en nueve. Los extranjeros que actuaron o gobernaron en Portugal también fueron incluidos, debiéndose destacar la presencia de los reyes Habsburgo españoles (Felipe II, con 25 retratos; Felipe III, con 18; y Felipe IV, con 32 grabados),

49 Monteiro y Caldeira, op. cit. (nota 13), pp. 88-90.

50 Ibidem. 
de sus reinas y del virrey Alberto de Austria, con cuatro grabados. Los académicos regios (los miembros fundadores, los que ingresaron más tarde o los supernumerarios que residían fuera de Lisboa) figuran en el álbum relativo a los varones insignes en letras, artes y ciencias: Manuel Telles da Silva (en un retrato), António dos Reis (en dos), Alexandre de Gusmão (uno), D. José de Portugal (uno), D. António Caetano de Sousa (uno), José Maria da Fonseca (tres), Manuel de Azevedo Fortes (uno), Diogo Barbosa Machado (dos) y su hermano Inácio (un retrato extraviado). En el álbum sobre personajes de campaña y gabinete, Diogo de Mendonça Corte Real y Sebastião José de Carvalho e Melo -ambos académicos- aparecen en dos retratos cada uno ${ }^{51}$.

Parece un cómputo modesto frente a la magnitud total de la colección, con sus 1382 retratos grabados. Con todo, conviene tener presentes los objetivos que probablemente se propuso Diogo Barbosa Machado al elaborar estos dos conjuntos documentales (retratos y folletos), su eventual recepción y los vínculos con sus principales grupos de inserción, tal y como planteábamos al inicio de este artículo. Como hemos visto, las colecciones de retratos y folletos no se hicieron para ser publicadas y tampoco formaron parte de los trabajos que se encomendaron a Diogo Barbosa Machado ${ }^{52}$. Mientras los retratos fueron recortados de otras obras impresas, que se mutilaron, los opúsculos, fácilmente perecederos, acabaron preservándose mejor al ser encuadernados, al modo de las colecciones académicas que acabaron en 1736. Barbosa Machado montó su colección de retratos después de componer el libro sobre el rey Sebastián y en medio de la publicación de los tomos de la Bibliotheca Lusitana. Por su parte, los folletos se encuadernaron al menos en 1770, cuando el coleccionista era ya octogenario y comenzaba la transferencia de su librería a la Real Biblioteca.

Barbosa Machado, por tanto, confeccionó sus estimadas colecciones en un momento de declive de la Academia Real da História Portuguesa ${ }^{53}$. Cabe pensar que las concibiese como un trabajo paulatino y de madurez, poniendo en ellas mucho de sí mismo (formación, gusto, expectativas), aunque presionado por las circunstancias y por el avanzar de la edad. Sin duda, el sistema académico se hizo patente en la elaboración de estas colecciones. En ellas, la historia secular surge diferenciada de la eclesiástica -por medio de sus personajes y hechos-, siendo apenas tratadas de forma conjunta cuando eran inseparables. No obstante, ambas historias, a pesar de haber sido exhaustivamente examinadas y clasificadas a través de la recopilación de grabados y escritos, asumían un tono laudatorio -en distintos tiempos y espacios- de la virtud heroica portuguesa y de algunos de sus protagonistas. Se forjaba así una re-

51 Véanse los anexos con los nombres de los académicos en MотA, op. cit. (nota 16), pp. 375-381.

52 Además de las memorias sobre Sebastián I, se le encomendaron trabajos sobre los reinados del cardenalrey Enrique de Avís y de los tres monarcas Habsburgo de Portugal, que no llegó a concluir.

53 A partir de 1730, se aprecia algún absentismo entre los académicos; desde 1734, la ceremonia de entrada de los nuevos miembros se hace en el palacio de la Ribeira; en 1736, con el fin de las colecçóes acadêmicas, será más difícil obtener informaciones sobre los académicos, renovados en 1750. El terremoto debe haber pesado en la vida de la Academia, ya que el palacio de la Ribeira, donde se reunía, ardió, así como su biblioteca. A su vez, la creación de la Real Mesa Censória, en 1768, supuso implementar una política de concentración de poderes en una única institución dependiente de la corona, desautorizando a los antiguos censores. En el reinado de José I, la producción histórica académica se redujo bastante. En 1779, la nueva Academia Real das Ciências se dedicaba, entre distintos ámbitos culturales, a la historiografía; ibidem, pp. 113-121. 
presentación narrativa de amplio espectro, pero que reunía piezas visuales y escritas, aisladas entre sí en el pasado y correspondientes a diversos momentos de producción. Estas piezas, muchas de ellas originalmente de carácter apologético, adquirieron nuevos significados con arreglo a los propósitos del coleccionista. Con todo, folletos y retratos conservarían algo de sus respectivos sentidos originales, como memorias particulares convertidas en un modo de escribir la historia ${ }^{54}$.

La experiencia como oratoriano de Diogo Barbosa Machado repercutió de modo más difuso en la composición de estos conjuntos documentales. Quizás quepa relacionarla con la propia libertad de que gozaban los miembros de la Congregación, presente, por ejemplo, en la creatividad que muestra el coleccionista. Los oratorianos, después de los teatinos, constituían un grupo de letrados distinguidos por su erudición en la Academia Real. No obstante, el abad de Sever desarrolló prácticas similares a las del académico correspondiente João Baptista de Castro, con su aprecio por los recortes, por la conjugación de materiales escritos y visuales, así como por la corografía de Portugal y de sus conquistas ${ }^{55}$. Lo cierto es que, en las colecciones aquí examinadas, tanto la geografía como la cronología actuaron como pilares de la historia, siendo éste un aspecto relacionado con los dos ámbitos de formación de Barbosa Machado. Cabe señalar, además, el interés por aproximarse a los grupos y elementos en ascenso o en el poder, asimismo característico de los oratorianos portugueses y de los académicos regios.

Del total de folletos reunidos, los documentos que aluden a hechos ocurridos en el mundo ultramarino portugués, constituyen apenas un $10 \%$, frente a una inmensa mayoría de sucesos relativos al ámbito europeo. En lo que concierne a los retratos, aunque en ellos la identificación de varios nombres sea más difícil de hacer, el número de personajes que actuaron en los dominios lusos de Asia, África o América se sitúa en torno al $25 \%$. Estas cuantías parecen apuntar a un discurso exaltador de las conquistas portuguesas y a una perspectiva de construcción de la identidad de la monarquía lusa sobre la base de sus vínculos con el mundo ultramarino, reflejando así

54 Reinhart Koselleck considera que la concepción moralizante de historia, como magistra vitae, al servicio de la educación de los príncipes, como instrumento diplomático o aparato jurídico y administrativo, fue siendo desplazada gradualmente a mediados del siglo XVIII. La secularización del discurso historiográfico en los estados alemanes hizo posible la convergencia entre el sentido de la historia como acontecimiento y como representación o narrativa. La transformación del orden semántico, que se observa en la lengua alemana, fundió el doble sentido de la palabra historia. La reducción transformó la historia en un arte o ciencia de representación del colectivo, capaz de superar las series cronológicas y de dotar a los hechos de estructuras causales, proporcionándoles una comprensión interpretativa global. Koselleck, R.: Futuro pasado. Para una semántica de los tiempos históricos, traducción de Norberto Smilg, Barcelona, Paidós, 1993, pp. 41-66; ID.: historia/Historia [1975], traducción e introducción de Antonio Gómez Ramos, Madrid, Trotta, 2004; KANTOR, op. cit. (nota 40), p. 78.

55 En la sección de cartografía de la Biblioteca Nacional de Brasil, hay un atlas ficticio, titulado Mappas do reino de Portugal e suas conquistas, que contiene 193 documentos, incluidos mapas, plantas, planos y vistas. La mayoría de los documentos son grabados en metal, retirados de obras publicadas. Infelizmente, su encuadernación se destruyó. Cabe suponer que el material no recibiese el mismo trato y dedicación que los opúsculos y los retratos. No obstante, permanece como objeto para futuros trabajos. FARIA, M. D.: "O atlas factício de Barbosa Machado". Disponible en https://www.ufmg.br/rededemuseus/crch/faria_o-atlas-facticiode-barbosa-machado.pdf (acceso: 10/11/2013). 
las preocupaciones geopolíticas de la época, pero también las intenciones del propio coleccionista ${ }^{56}$.

Entre tanto, a la hora de buscar un sentido predominante de análisis, no se puede olvidar el destino que tuvieron estos dos conjuntos documentales, sumamente estimados e incorporados al acervo de la Real Biblioteca tras los daños del terremoto de 1755. El suceso debe haber influido sobremanera en el afán compilador de Barbosa Machado, dada la destrucción que produjo en Lisboa, incluida la biblioteca regia. Como hemos visto, los miembros portugueses de la Congregación del Oratorio se distinguieron por el prestigio adquirido durante la primera mitad del Setecientos, al constituir una vía de erudición renovada. Tanto en los retratos como en los folletos coleccionados por el oratoriano y académico real, los reyes, reinas y príncipes de Portugal son los protagonistas indiscutibles, situados en primer lugar y comprendiendo el mayor número de documentos. De entre todos, destaca la figura de Juan V, con 37 retratos y 247 folletos en los que figura como personaje principal, además de los 50 opúsculos que le son dedicados. Este protagonismo joanino, incluso con respecto a José I (el rey a quien donó la librería), se explica por el tiempo en el que se confeccionaron ambas colecciones. Sobre todo la de retratos, cuyos dos álbumes relativos a los reyes y príncipes datan de 1746 . Pero, no sólo. Ese protagonismo hace referencia a una cultura de emblemas, estampas y textos conmemorativos que habría de conocer una particular proyección durante aquel reinado, sobre todo cuando se vinculaba a la historia ${ }^{57}$. El carácter espontáneo y positivo de esa producción, cuando se confrontó con los nuevos desafíos políticos de la época pombalina, no tendría ya continuidad.

Es en la confluencia de estos aspectos donde se debe buscar el espíritu de estos elaborados conjuntos documentales, que no fueron sino resultado de los itinerarios que incidieron sobre la formación de su autor/coleccionador, así como de las experiencias que éste vivió, de los cambios físicos, institucionales y políticos, y de sus expectativas de reconocimiento postrero. Al final, en el Antiguo Régimen portugués, los reyes contaban la historia, al ordenar epistemológicamente el tempo y los espacios. Cabe así pensar que el clérigo y erudito del siglo XVIII quisiera hacer de sus particulares colecciones un gran "oratorio regio", secundado, al menos en los retratos, por santos y letrados.

Traducción del portugués: Federico PaLOMO

\footnotetext{
56 Estas preocupaciones geográficas, en el caso de Diogo Barbosa Machado, eran propias del perfil ilustrado que se le puede atribuir, como en el caso de D. Luís da Cunha, embajador y académico real, estudiado por Júnia Furtado. Como hemos visto, el abad de Sever era un hombre orientado al pasado, y no un oráculo del futuro, cuyos métodos atacaría Verney, a pesar de distinguirse por alguna erudición de moldes dieciochescos. FuRTADO, J. F.: Oráculos da geografia iluminista. Dom Luís da Cunha e Jean-Baptiste Bourguignon D'Anville na construção da cartografia do Brasil, Belo Horizonte, Editora da UFMG, 2012, pp. 71-144.

57 Mandroux-França, M. T. (org.): Catalogues de la collection d'estampes de Jean V, roi de Portugal par Pierre-Jean Mariette, 3 vols., Lisboa-París, Fundação Calouste Gulbenkian/Bibliothèque Nationale de France/Fundação Casa de Bragança, 1996.
} 


\section{RETRATOS}

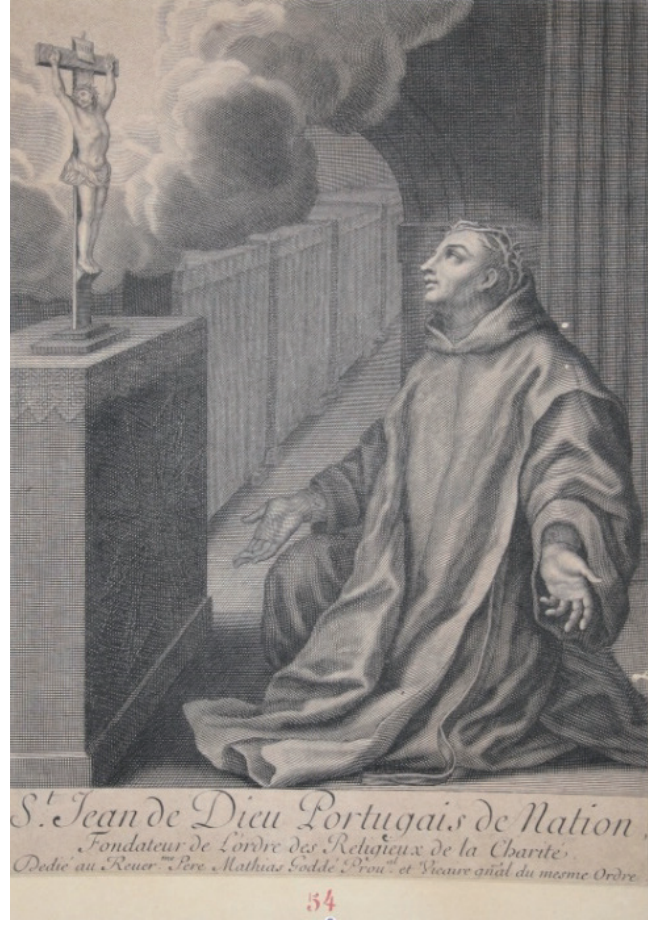

Fig. 1.

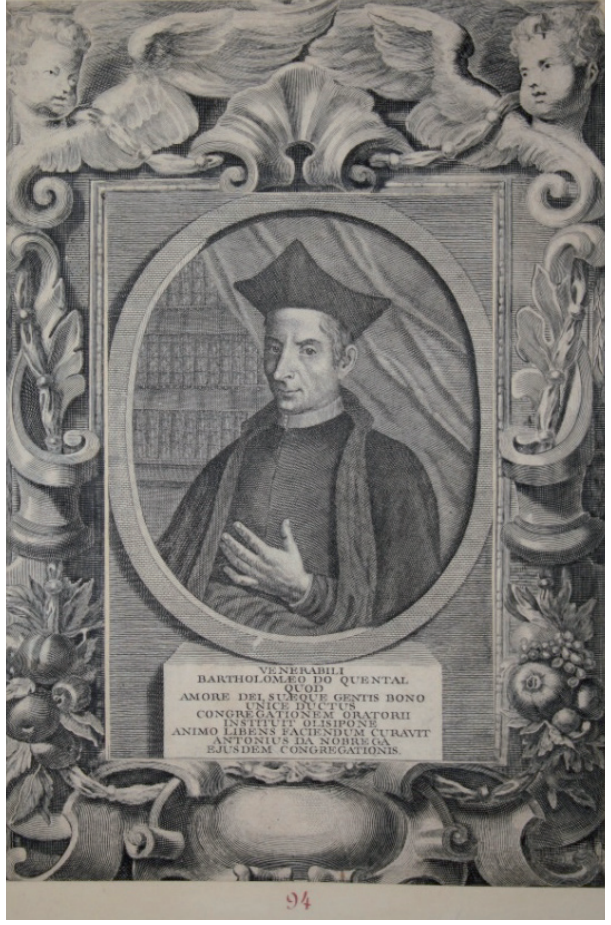

Fig. 2.

Fig. 1. Grabado francés de Juan de Dios que subraya su origen lusitano, conforme a los criterios inclusivos de la Academia Real da História. Esta gran figura, que inspiró a la Congregación del Oratorio, aparece en 17 retratos del tomo III, dedicado a los varones portugueses insignes en virtudes y dignidades. BNB, Río de Janeiro.

Fig. 2. Ya en el tomo IV de la colección de retratos, relativo a los varones insignes en letras, artes y ciencias, existe un grabado anónimo y sin fecha de Bartolomeu de Quental, rodeado por una orla. El orador y fundador de la Congregación aparece en siete ocasiones en este tomo, igualando el número de retratos de António Vieira. En la colección de folletos, sin embargo, hay apenas un sermón publicado con su nombre, a mucha distancia de los 24 de autoría del jesuita. Al fondo, un estante con libros otorga dignidad al religioso y letrado. En la Bibliotheca Lusitana, Barbosa Machado subraya la integridad de su vida. BNB, Río de Janeiro. 


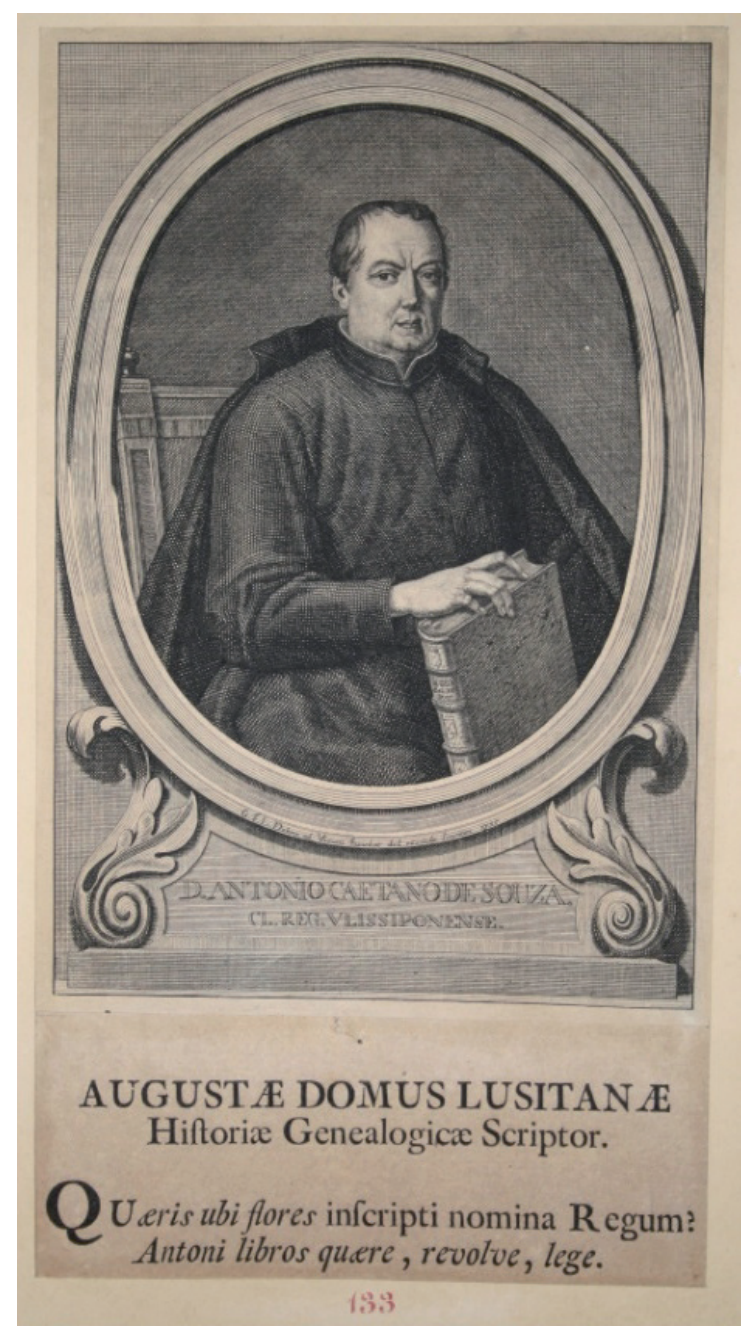

Fig. 3. En el mismo tomo, el único retrato del teatino y académico real D. António Caetano de Sousa (1674-1759), que aparece, dentro de un óvalo, sosteniendo un volumen de su História genealógica da casa real Portuguesa, obra de la que se retiró el propio grabado, realizado en 1735 por Guillaume François Laurent Debrie, pintor y grabador francés que realizó una larga estancia en Portugal. Al grabado, Barbosa Machado le añadió un epigrama laudatorio recortado y pegado debajo. De acuerdo con la Bibliotheca Lusitana, Caetano de Sousa tuvo influencias del "príncipe de los genealógistas" D. Luis Salazar y Castro. En la Academia se le encargó además escribir las memorias de los obispados ultramarinos, aunque fue más conocido como autor de la obra con la que está relacionado el retrato, publicada en seis tomos, entre 1735 e 1739. BNB, Río de Janeiro. 


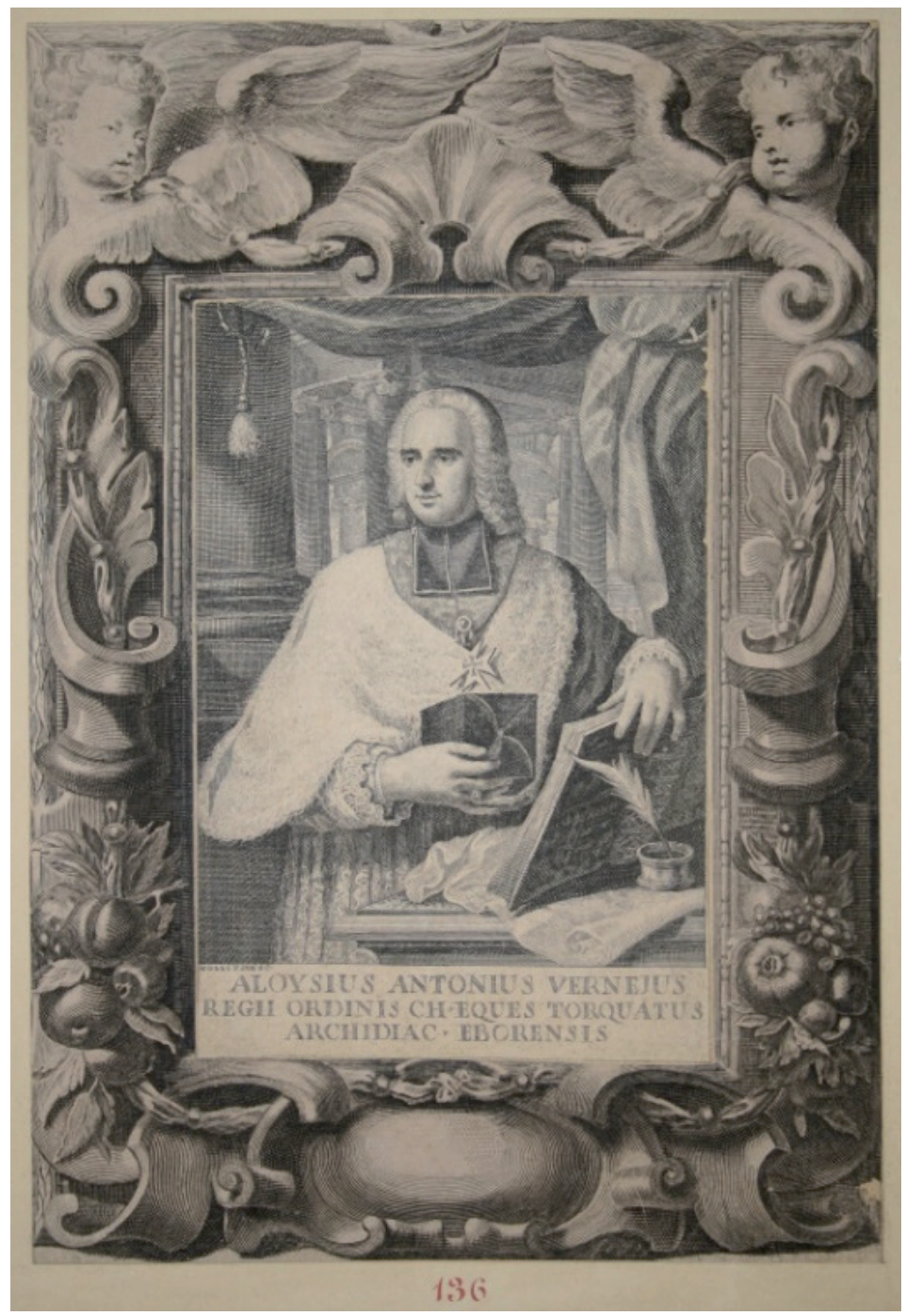

Fig. 4. Único retrato en el mismo tomo de la colección de Luís António Verney (1713-1792), que, rodeado por una orla, aparece vestido con sobrepelliz y con el hábito de caballero de la Orden de Cristo. En la Bibliotheca Lusitana, Diogo Barbosa Machado menciona su formación con los oratorianos. No obstante, Verney criticó al académico real y coleccionista por sus métodos anticuados. BNB, Río de Janeiro. 


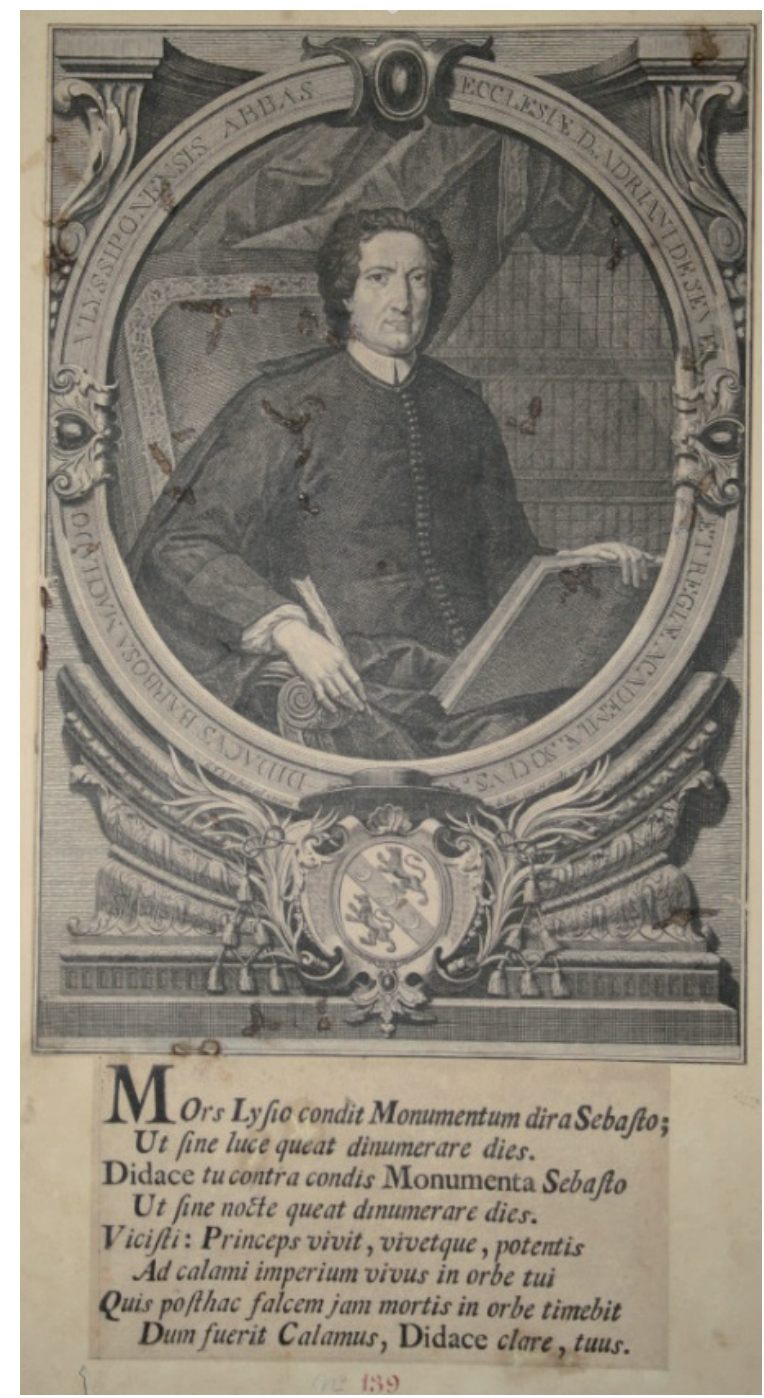

Fig. 5. También en el mismo tomo, retrato de Diogo Barbosa Machado, realizado por Guillaume F. L. Debrie, em 1741, a partir del cuadro al óleo de Kelberg. En él, el abad de Sever aparece, dentro de un óvalo, rodeado de libros y elementos propios del letrado, además del capelo abacial con borlas y las armas de los Barbosa. A la composición se le añadió por debajo, recortado, un epigrama laudatorio en latín. El académico real figura en dos retratos de su propia colección. Este grabado se rechazó como estampa para el primer volumen de la Bibliotheca Lusitana, en favor de otra, realizada por Thomassin, en la que el académico real aparece envejecido, más acorde a la edad que tenía en la época. BNB, Río de Janeiro. 